\title{
Amplifying and Fine-Tuning Rsm sRNAs Expression and Stability to Optimize the Survival of Pseudomonas brassicacerum in Nutrient-Poor Environments
}

\author{
David Lalaouna ${ }^{1,2}\left(\mathbb{D}\right.$, Sylvain Fochesato ${ }^{1}$, Mourad Harir ${ }^{3,4}$, Philippe Ortet ${ }^{1}{ }^{(D}$, Philippe Schmitt-Kopplin ${ }^{3,4}$, \\ Thierry Heulin ${ }^{1}$ (D) and Wafa Achouak ${ }^{1, * \mathbb{D}}$ \\ 1 Aix Marseille Univ, CEA, CNRS, BIAM, Lab Microbial Ecology of the Rhizosphere (LEMiRE), \\ F-13108 Saint-Paul-Lez-Durance, France; d.lalaouna@ibmc-cnrs.unistra.fr (D.L.); \\ sylvain.fochesato@cea.fr (S.F.); Philippe.ortet@cea.fr (P.O.); thierry.heulin@cea.fr (T.H.) \\ 2 Université de Strasbourg, CNRS, ARN UPR 9002, F-67000 Strasbourg, France \\ 3 Research Unit Analytical BioGeoChemistry, Helmholtz Zentrum München, 85764 Neuherberg, Germany; \\ mourad.harir@helmholtz-muenchen.de (M.H.); schmitt-kopplin@helmholtz-muenchen.de (P.S.-K.) \\ 4 Technical University of Munich, Maximus-von-Imhof-Forum 2, 85354 Freising, Germany \\ * Correspondence: wafa.achouak@cea.fr; Tel.: +33-442254961
}

\section{check for} updates

Citation: Lalaouna, D.; Fochesato, S.; Harir, M.; Ortet, P.;

Schmitt-Kopplin, P.; Heulin, T.;

Achouak, W. Amplifying and

Fine-Tuning Rsm sRNAs Expression

and Stability to Optimize the Survival

of Pseudomonas brassicacerum in

Nutrient-Poor Environments.

Microorganisms 2021, 9, 250.

https://doi.org/10.3390/

microorganisms 9020250

Academic Editor: Jacob G. Malone

Received: 1 January 2021

Accepted: 19 January 2021

Published: 26 January 2021

Publisher's Note: MDPI stays neutral with regard to jurisdictional claims in published maps and institutional affiliations.

Copyright: (c) 2021 by the authors. Licensee MDPI, Basel, Switzerland. This article is an open access article distributed under the terms and conditions of the Creative Commons Attribution (CC BY) license (https:// creativecommons.org/licenses/by/ $4.0 /)$.
Abstract: In the beneficial plant root-associated Pseudomonas brassicacearum strain NFM421, the GacS/GacA two-component system positively controls biofilm formation and the production of secondary metabolites through the synthesis of $r s m X, r s m Y$ and $r s m Z$. Here, we evidenced the genetic amplification of Rsm sRNAs by the discovery of a novel 110-nt long sRNA encoding gene, $r s m X-2$, generated by the duplication of $r s m X-1$ (formerly $r s m X$ ). Like the others $r s m$ genes, its overexpression overrides the gacA mutation. We explored the expression and the stability of $r s m X-1, r s m X-2, r s m Y$ and $r s m Z$ encoding genes under rich or nutrient-poor conditions, and showed that their amount is fine-tuned at the transcriptional and more interestingly at the post-transcriptional level. Unlike $r s m Y$ and $r s m Z$, we noticed that the expression of $r s m X-1$ and $r s m X-2$ genes was exclusively GacAdependent. The highest expression level and longest half-life for each sRNA were correlated with the highest ppGpp and cyclic-di-GMP levels and were recorded under nutrient-poor conditions. Together, these data support the view that the Rsm system in P. brassicacearum is likely linked to the stringent response, and seems to be required for bacterial adaptation to nutritional stress.

Keywords: Rsm sRNAs; Pseudomonas brassicacearum; sRNAs stability; nutritional stress; GacA-dependent

\section{Introduction}

The RNA-binding protein CsrA (carbon storage regulator) and its homolog RsmA (regulator of secondary metabolites) regulate a variety of genes at the post-transcriptional level. Their regulatory activity is modulated by regulatory small RNA (sRNA) antagonists of CsrA/RsmA. Functional homologs of the Csr/Rsm system have been discovered in many Gram-negative genera, including Escherichia [1], Salmonella [2], Vibrio [3], Legionella [4], Yersinia [5] and Pseudomonas [6-8], as well as in some Gram-positive bacteria such as the Bacillus genus [9].

The wide distribution of the Csr/Rsm regulatory system in Eubacteria, including animal/plant pathogenic species as well as plant growth-promoting rhizobacteria (PGPR), illustrates that this well-conserved system is involved in various essential functions $[10,11]$. Indeed, small RNAs positively controlled by either the BarA/UvrY or GacS/GacA twocomponent systems have been shown to regulate various functions by coordinating the expression of a set of target genes post-transcriptionally [12,13]

The number and size of sRNAs involved in this system are variable. In Escherichia coli, the protein repressor CsrA is regulated by two sRNAs, CsrB and CsrC. These sRNAs 
sequester CsrA by mimicking its recognition sequence [14,15]. Here, CsrB sRNA, a 360nucleotide long RNA, works in concert with CsrC sRNA (250 nts). Two homologs were found in Pseudomonas aeruginosa and named RsmY (124 nt) and RsmZ (115 nt) [7]. A third Rsm sRNA, RsmX (119 nt), was discovered in Pseudomonas protegens (formerly Pseudomonas fluorescens) CHA0 [6] and predicted to be found in other species including P. fluorescens Pf-5, P. fluorescens Pf0-1, Pseudomonas putida KT2440 and Pseudomonas syringae pv. tomato DC3000. Surprisingly, up to five RsmX encoding genes have been described in P. syringae [8]. Moreover, experiments with artificial RsmY-like sRNAs have demonstrated that conservation of size and/or primary sequence is not essential for Rsm functions [16]. In fact, the regulatory mechanism is linked to appropriate exposure of mimicked CsrA/RsmA recognition motif.

In general, Csr and Rsm sRNAs seem to be redundant $[7,17,18]$. However, although all Rsm sRNAs are positively controlled by GacA, additional regulators have been identified, such as PsrA, which activates rsmZ in P. protegens CHA0 [19] and HptB, which exclusively controls $r s m Y$ in P. aeruginosa [20]. These additional regulators certainly enable a fine-tuning control by integrating various signals.

We have previously, shown that spontaneous mutations in either gacS or gacA in $P$. brassicacearum can alter many phenotypes typically associated with phytobeneficial traits, as well as root colonization and modification of the root architecture [18,21-23]. These traits include secretion of exoenzymes such as protease and lipase [24], production of antifungal metabolites (DAPG and cyanide) and N-acyl-homoserine lactones, the phytohormone auxin, biofilm formation, alginate production, chemotaxis, and type VI secretion [18]. In addition, overexpression of either $r s m X, r s m Y$, or $r s m Z$ fully suppressed the pleiotropic gacA or gacS mutations and restored the WT phenotypes in P. brassicacearum variants [18].

The primary goal of this study was to determine whether P. brassicacearum genome encodes other Rsm sRNAs and whether their overexpression could override the gacA or gacS mutation. The second part of our work aimed at evaluating the expression and stability of Rsm sRNAs under conditions of different nutrient levels. Finally, to establish the reliability of the results, the analysis of metabolites involved in stringency and biofilm formation was carried out.

\section{Experimental Procedures}

\subsection{Bacterial Strains, Plasmids and Growth Conditions}

The bacterial strains and plasmids used in this study are listed in Table S1. P. brassicacearum NFM 421 and gacA mutant were grown as described in Lalaouna et al. [18]. Escherichia coli GM2163, TOP10 and S17-1 strains were grown in LB medium at $37^{\circ} \mathrm{C}$.

In order to test influences of carbon availability, bacterial strains were grown in TSB (BD), TSB/10 and TSB/20 media. For growth on plates, media were solidified with $15 \mathrm{~g} / \mathrm{L}$ agar (Sigma, St. Louis, USA). Pseudomonas agar F (PAF) (Difco) was used to compare bacterial colony morphology of NFM421 WT, gacS and gacA mutants.

\subsection{DNA Manipulation}

Chromosomal DNA from P. brassicacearum NFM421 was prepared by phenol/ chloroform extraction. Plasmid extraction using the "QIAprep Spin Miniprep Kit" (Qiagen, Hilden, Germany), and purification of DNA fragments from agarose gels with the "QIAquick Gel extraction Kit" (Qiagen, Hilden, Germany) were performed according to the manufacturer's instructions.

\subsection{RNA Manipulation}

For RNA extractions, we used "RNAprotect Bacteria Reagent" and "RNeasy Mini Kit" (Qiagen, Hilden, Germany). RT-PCR assays were performed with the "Transcriptor First Strand cDNA Synthesis Kit" (Roche, Manheim, Germany). Gene-specific primers for real-time PCR were designed based on P. brassicacearum NFM421 rsmX-1, rsmX-2, rsm Y and rsmZ sequences to obtain predicted PCR products of 200-250 bases (Table S1). Amplifications were performed according to the real Q-PCR Light Cycler 480 SYBR Green 
I Master kit instructions for the Light Cycler 480 Real Time PCR System (Roche). Real-time $\mathrm{PCR}$ was performed in triplicate, and mRNA relative expression was normalized to the $16 \mathrm{~S}$ reference gene.

\section{4. $5^{\prime} R A C E$}

The $5^{\prime}$-end of the $r s m X-2$ transcript was mapped by RACE. Total RNA from P. brassicacearum strain NFM421 isolated in late stationary phase was used for a reverse transcription reaction with the Transcriptor First Strand cDNA Synthesis Kit (Roche, Manheim, Germany). The 5'-phosphorylated, 3'-end cordecypin-blocked oligonucleotide DT88 [25] was ligated to the single-strand cDNA with T4 RNA ligase (New England Biolabs, Ipswich, USA). The anchor-ligated cDNA was first amplified with primers DT89 (anchor-specific primer) and a $r s m X-2$-specific primer ( $r s m X-2-R 1$; Table S1). Next, a nested PCR was performed using DT89 and a second $r s m$-specific internal primer ( $r s m X-2-\mathrm{R} 2)$. Finally, the PCR product was cloned into the cloning vector $\mathrm{PCR}^{\circledR} 4 \mathrm{Blunt}^{-\mathrm{TOPO}}{ }^{\circledR}$ (Thermo Fisher Scientific, Waltham, USA). Three independent clones were sequenced using T7 primer (GATC Biotech, Konstanz, Germany).

\subsection{Overexpression of $s R N A s$}

To overexpress $r s m X-2$, we used the pME6032 plasmid [26]. The Shine-Dalgarno sequence was removed, as it is unsuitable for the expression of small RNAs. The rsmX-2 gene was amplified from chromosomal DNA by PCR using primers $r s m X-2$-PstI and $r s m X$ 2-KpnI (Table S1), digested by PstI and KpnI, and inserted into PstI/KpnI-cut pME6032. The introduction of the PstI restriction site adds $5 \mathrm{nt}$ and modifies $1 \mathrm{nt}$ of the RsmX-2 sRNA at the $5^{\prime}$ end $\left(5^{\prime}\right.$-CTGCAGCCACTG $\ldots$ in place of $5^{\prime}$-TCCACTG). All mutations were verified by sequencing the inserts.

\subsection{Construction of Transcriptional lacZ Fusions}

To construct the $r s m X-2+16$ transcriptional fusion, we amplified the promoter region and the first 16 nts of rsmX-2 sequence by PCR with primers listed in Table S1. The PCR products were subsequently digested with specific restriction enzymes and cloned into pME6016 plasmids [27] and then sequenced. The pME6016-rsmX-2-lacZ plasmid was introduced into competent cells of NFM421 strain by electroporation ( $(2500 \mathrm{~V}$ for $5 \mathrm{~ms}$ using an Eppendorf Multiporator ${ }^{\circledR}$ electroporator, Hambourg, Germany).

\subsection{Northern Blot Analysis}

RNA was extracted from overnight cultures of NFM421 WT strain and from $\triangle g a c A$ mutant using "RNeasy Mini Kit" (Qiagen, Hambourg, Germany). The electrophoresis of total RNA was performed on a polyacrylamide gel (5\% acrylamide 29:1, $8 \mathrm{M}$ urea). RNAs were then transferred on a Hybond $\mathrm{N}+$ nitrocellulose membrane (GE Healthcare Life Sciences, Uppsala, Swenden). RsmX-2 or 5S-specific digoxygenin-labelled probes were used (Table S1). 5S rRNA was used as loading control. Luminescent detection was carried out as previously described [28].

\subsection{Protease Activity Assays}

In order to detect the extracellular protease activity, the bacteria are inoculated on TSB / 10 solid medium containing $1 \%$ skim milk powder (TSA lec). The presence of a halo around the colony attests to protease activity.

\section{9. $\beta$-Galactosidase Assays}

Cultures containing a rsmX-2 + 16-lacZ construct were grown overnight, diluted 1:200 into $8 \mathrm{~mL}$ of TSB with tetracycline $(20 \mu \mathrm{g} / \mathrm{mL})$, and grown over a period of $24 \mathrm{~h}$. For the time-course of $r s m X-2$ expression, $50 \mathrm{~mL}$ cultures were sampled at different times and assayed immediately. $\beta$-galactosidase activities were quantified as previously described [18]. Experiments were conducted in triplicates. 


\subsection{Biofilm Assays}

As previously described [18], overnight cultures were diluted to $\mathrm{OD}_{600 \mathrm{~nm}}=0.05$ in K10T-1 medium [29] and $1 \mathrm{~mL}$ aliquots were dispensed into glass tubes in triplicate. Following static incubation at $30^{\circ} \mathrm{C}$, the medium was removed, and tubes were washed gently with distilled water. Biofilm formation was visualized by crystal violet staining.

\subsection{Stability of Rsm sRNAs}

Wild-type cells were grown in TSB/10 or TSB media. To arrest RNA transcription, rifampicin was added at a final concentration of $200 \mu \mathrm{g} / \mathrm{mL}$, either in early stationary phase $\left(\mathrm{OD}_{600 \mathrm{~nm}} 1.5\right.$ in TSB and 0.5 in TSB/10) or in late stationary phase $\left(\mathrm{OD}_{600 \mathrm{~nm}} 4.5\right.$ in TSB and 0.9 in TSB/10). At different time points $(1,2,5,10,15,20,30,45,60,90$ and $120 \mathrm{~min}$ ), $0.5 \mathrm{~mL}$ from each sample was mixed with $1 \mathrm{~mL}$ of RNA protect (Qiagen, Hilden, Germany), and total RNAs were extracted as described above. TURBO DNase treatment following reverse transcription, TaqMan real-time PCR analysis was used to determine the amount of each Rsm.

TaqMan PCR reactions were performed as described in the "LightCycler ${ }^{\circledR} 480$ Probes Master" (Roche) protocol, with double-labelled oligonucleotide probe (FAM and TAMRA dyes in $5^{\prime}$ and $3^{\prime}$ ends, respectively; Eurogentec). Reactions were run in a LightCycler ${ }^{\circledR}$ 480 System. Threshold detection parameters were determined using the second derivative method. PCR efficiencies were determined by amplification of four 10-fold serial dilutions of all target sequences. Triplicated biological samples were quantified, and mean values were used to express Rsm sRNAs abundance relative to 16S RNA.

\subsection{High Resolution Mass Spectrometry Analysis}

WT cells were grown in TSB/20, TSB/10 or TSB media. Cells were harvested in late stationary phase and washed with ultrapure water. The lyophilized samples were extracted in methanol water (v:v) in an ultrasonic bath for $15 \mathrm{~min}$. The pellets were centrifuged at 14,000 rpm for $5 \mathrm{~min}$ and the supernatants were analyzed in negative mode using 12 Tesla SOLARIX Fourier transform ion cyclotrom mass spectrometer (FT-ICR/MS) from Bruker Daltonics, Bremen, Germany. The injections were performed using a micro-liter pump at a liquid flow rate of $120 \mu \mathrm{L} \mathrm{h}^{-1}$. Nitrogen was used for both sheath gas as well as curtain gas. A source heater temperature of $200{ }^{\circ} \mathrm{C}$ was maintained to ensure rapid solvent evaporation in the ionized droplets. Data acquisition and handling were performed by using Data Analysis Software from Bruker (Bruker Daltonics, Bremen, Germany).

\subsection{MassTRIX Metabolite Annotation}

Samples were annotated to possible metabolites of $P$. brassicacearum using the KEGG metabolome database. The exact mass lists (asc files) were uploaded and compared with a $1.0 \mathrm{ppm}$ accuracy window to the metabolome mass translator into pathways (MassTRIX) [30].

\section{Results}

\subsection{Identification of a Fourth Rsm sRNA in P. brassicacearum}

We identified a fourth Rsm sRNA by performing a BLAST search against the P. brassicacearum NFM421 genome and using the upstream activating sequence (UAS; TATAGCGAAACGCTTACA) recognized by GacA as query sequence. This revealed an additional UAS located upstream the gene encoding a putative sRNA (Figure 1A), which shares $75 \%$ similarity with $r s m X$ gene, while the UAS sequence is almost identical (Figure 1B). We renamed RsmX to RsmX-1, and the novel Rsm sRNA was named RsmX-2. The secondary structure of RsmX-2 was predicted with RNAfold and visualized using vaRNA software [31]. At least three potentially mimicked recognition motifs of RsmA/E (i.e., ANGGA or AGGA motifs) [32], are exposed within a hairpin loop, suggesting that RsmX-2 could sequester these proteins (Figure 1C). 
A

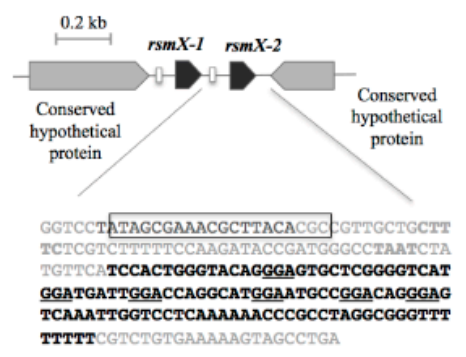

B

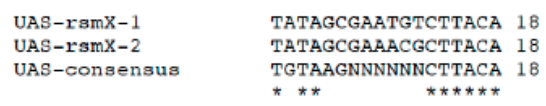

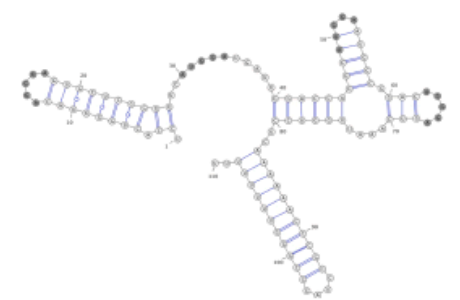

Figure 1. $r s m X-2$ identification and predicted structure. (A) Organization of the $r s m X-1$ and $r s m X-2$ genomic region of P. brassicacearum. The upstream activating sequence (UAS) of the GacA protein is represented within the box. GGA motifs involved in the sequestration of RsmA/E proteins are underlined. The transcriptional start has been determined by $5^{\prime} \mathrm{RACE}$ method. $r s m X-2$ gene sequence is indicated in bold; (B) Alignment of $r s m X-1$ and $r s m X-2$ UAS sequence; (C) rsmX-2 secondary structure predicted using RNAfold and visualised using vaRNA.

To determine, the relationship and evolutionary history, we performed a phylogenetic analysis of Rsm sRNAs genes. Phylogenetic tree Unweighted Pair Group Method with Arithmetic Mean (UPGMA) tree was constructed using MAFFT toolkit with a modified version of UPGMA. Rsm sRNAs exhibit a remarkably uniform distribution among Pseudomonas species. The UPGMA phylogenetic tree shows that $\operatorname{rsm} X, \operatorname{rsm} Y$ and $\operatorname{rsm} Z$ are sorted into three clades (Figure 2).

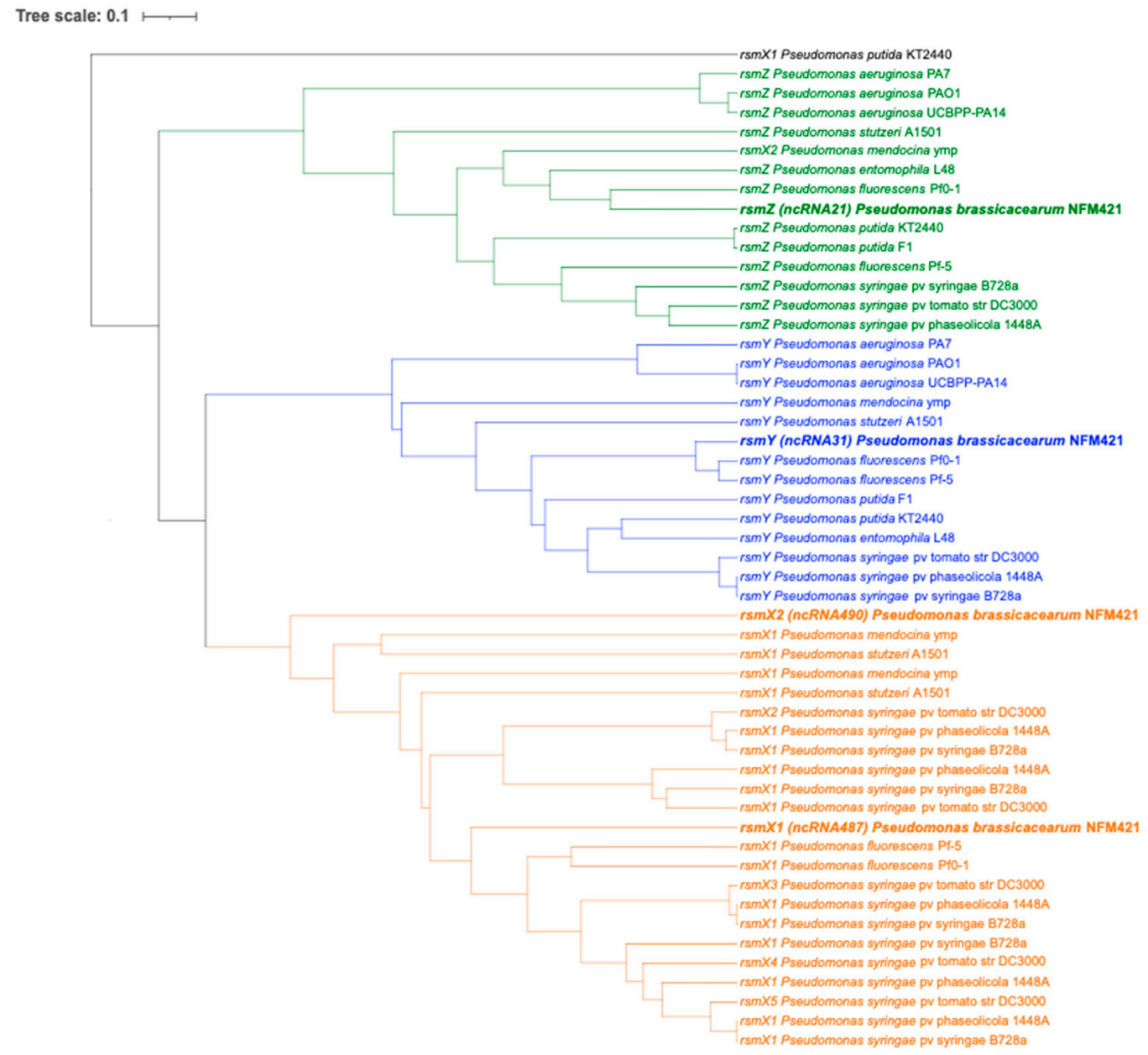

Figure 2. Phylogenetic analysis of $r s m$ RNA sequences. rsm genes from P. brassicacearum NFM 421 are shown in bold. 
Typically, Pseudomonads contain single copies of RsmY and RsmZ, however, the copy number of RsmX is variable. P. protegens CHA0 possesses one copy of RsmX [6], while $P$. syringae contains up to five copies [8]. In this study we identified a fourth Rsm RNA in P. brassicacearum NFM421 found in tandem with $r s m X$ with which it shares $75 \%$ of sequence identity. We also show a potential fourth Rsm sRNA in P. fluorescens F113 and Pseudomonas stutzeri, which are in tandem with $r s m X$ and share $75 \%$ and $81 \%$ sequence identity respectively (Table 1 ).

Table 1. Tandem copy of rsmX gene in Pseudomonas.

\begin{tabular}{|c|c|c|c|c|c|c|}
\hline Strains & Gene & Begin & End & Size (nt) & $\begin{array}{c}\text { Sequence } \\
\text { Identity }(\%)\end{array}$ & $\begin{array}{c}\text { Number of } \\
\text { rsmX-Like } \\
\text { Genes }\end{array}$ \\
\hline \multirow{2}{*}{ Pseudomonas brassicacearum NFM421 } & $r s m X-1$ & 4839892 & 4840003 & 111 & \multirow{2}{*}{75} & \multirow{2}{*}{2} \\
\hline & rsmX-2 & 4839681 & 4839791 & 110 & & \\
\hline \multirow{2}{*}{ Pseudomonas fluorescens F113 } & $r s m X-1 *$ & 2113839 & 2113950 & 111 & \multirow{2}{*}{75} & \multirow[b]{2}{*}{2} \\
\hline & $\operatorname{rsm} X-2 *$ & 2114052 & 2114160 & 108 & & \\
\hline \multirow{2}{*}{ Pseudomonas stutzeri A150 } & $\operatorname{rsm} X-1^{*}$ & 356904 & 357013 & 109 & \multirow{2}{*}{81.5} & \multirow[b]{2}{*}{2} \\
\hline & $r s m X-2$ * & 357143 & 357250 & 107 & & \\
\hline \multirow{2}{*}{$\begin{array}{c}\text { Pseudomonas syringae pv. phaseolicola } \\
1448 \mathrm{~A}\end{array}$} & $\operatorname{rsm} X-4^{* *}$ & 160448 & 160336 & 112 & \multirow{2}{*}{85} & \multirow{2}{*}{5} \\
\hline & $\operatorname{rsm} X-3$ ** & 160740 & 160627 & 113 & & \\
\hline \multirow{2}{*}{$\begin{array}{c}\text { Pseudomonas syringae pv. syringae } \\
\text { B728a }\end{array}$} & $\operatorname{rsm} X-3^{* *}$ & 5867169 & 5867282 & 113 & \multirow{2}{*}{84} & \multirow{2}{*}{5} \\
\hline & $\operatorname{rsm} X-4^{* *}$ & 5867461 & 5867572 & 111 & & \\
\hline \multirow{2}{*}{$\begin{array}{c}\text { Pseudomonas syringae pv. tomato str. } \\
\text { DC } 3000\end{array}$} & rsmX-3 & 6144830 & 6144943 & 113 & \multirow{2}{*}{87} & \multirow{2}{*}{5} \\
\hline & $\operatorname{rsm} X-4$ & 6145122 & 6145235 & 113 & & \\
\hline
\end{tabular}

* in comparison to P. brassicacearum NFM421. ** in comparison to P. syringae pv. tomato str. DC3000.

\section{2. rsmX-2 Expression Is Exclusively GacA-Dependent}

The Northern blot analysis (Figure $3 \mathrm{~A}$ ) and $5^{\prime}$ end determination of the transcript by $5^{\prime}$ RACE method confirmed that the novel 110-nt long Rsm sRNA is transcribed only in WT and not in the $\triangle g a c A$ mutant. This was confirmed by the analysis of $r s m X-2$ expression in wild-type and $\triangle g a c A$ mutant cells during growth in 10-fold diluted TSB medium, by measuring $\beta$-galactosidase activity of the transcriptional rsmX-2 +16 -lac $Z$ fusion (Figure 3B).

A

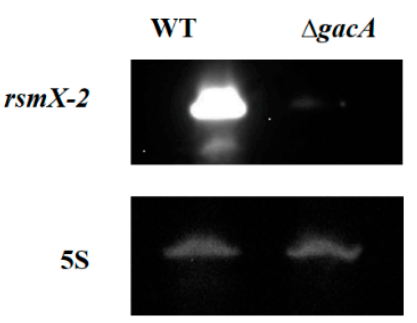

B

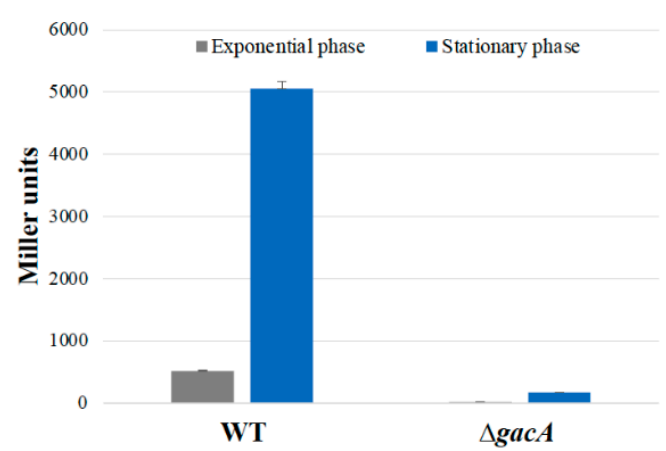

Figure 3. $r s m X-2$ expression is GacA dependent. (A) Northern blot analysis of $r s m X-2$ expression in WT and gacA backgrounds, 5S rRNA is used as loading control; (B) $\beta$-galactosidase measurements of a transcriptional rsmX-2 +16 -lacZ fusion in the WT and $\triangle g a c A$ strains.

Moreover, the overexpression of $r s m X-2$ from a vector under the control of Ptac promoter restored the wild-type phenotype in gac A mutant cells (Figure 4), indicating that the overall function of RsmX-2 is likely similar to that of RsmX-1, RsmY and RsmZ [18]. 
This is illustrated by the restoration of protease activity (Figure 4A), colony morphology (Figure 4B) and biofilm formation in a gacA mutant (Figure 4C). These findings indicate that RsmX-2 is part of the Gac-Rsm regulatory system.
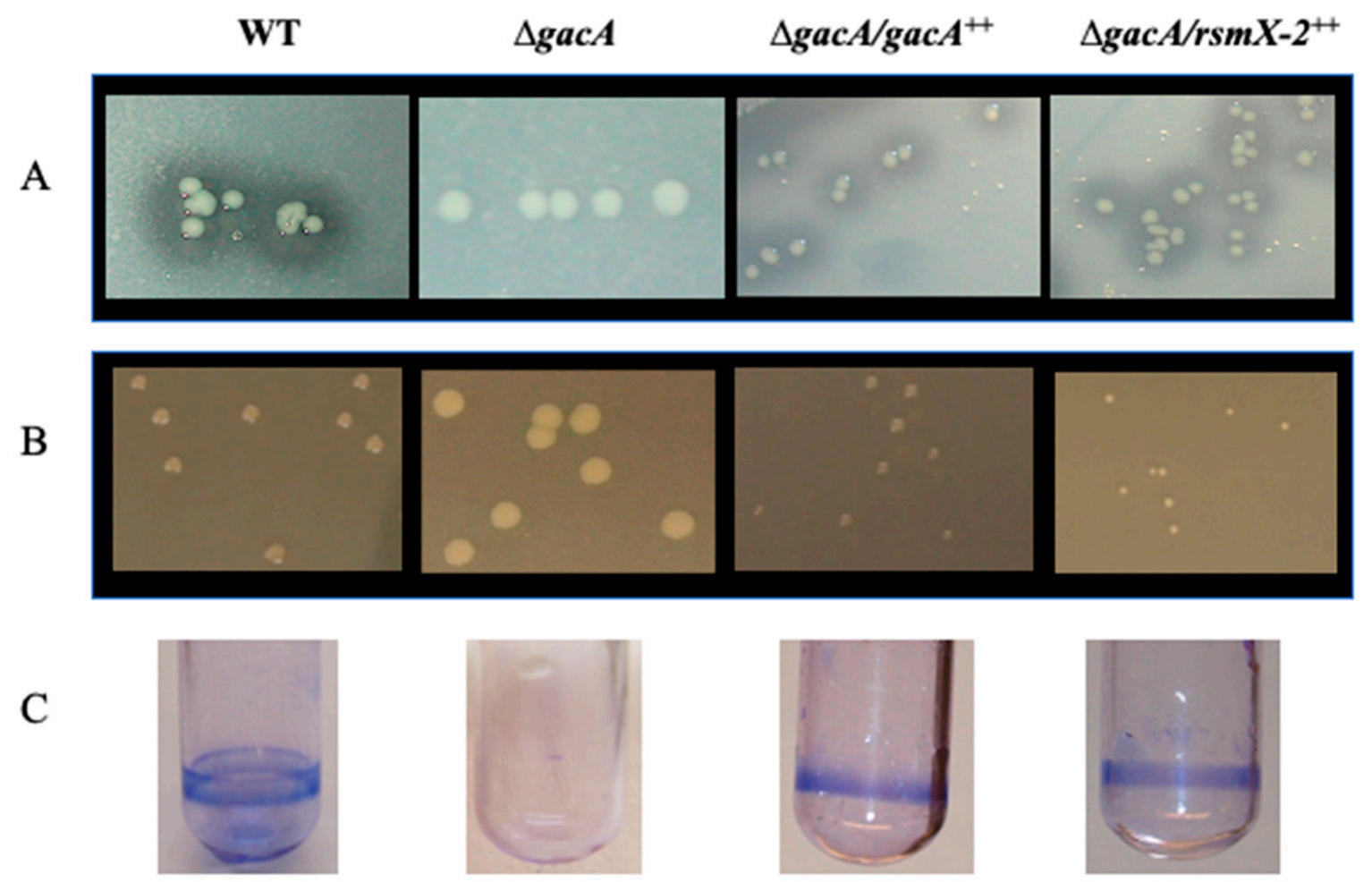

Figure 4. $r s m X-2$ restores GacA-dependent phenotypes. Restoration of wild-type phenotype by overexpression of $r s m X-2$ from a plasmid under the control of Ptac promoter in gacA cells as determined by (A) Protease activity on skimmed milk-containing medium, (B) Colony morphology on PAF medium and (C) Biofilm formation.

\subsection{Stringent Conditions Activate rsm sRNAs Genes Expression}

The expression of the four $r s m$ genes $r s m X-1, r s m X-2, r s m Y$ and $r s m Z$ increases over time until a maximum is reached in stationary phase ( $24 \mathrm{~h}$ of growth), when nutrients become limited. We therefore wondered whether carbon deprivation could activate the rsm expression, as previously reported for the Csr system [33]. To assess the biological relevance of these observations, we monitored the expression level of the four $r s m$ genes under different nutrient level conditions. Here, bacteria were grown in either undiluted TSB medium (considered as a rich medium), 10-fold diluted TSB (TSB/10), or 20-fold diluted TSB (TSB / 20) (which was considered as a nutrient-poor medium in which P. brassicacearum growth may occur). Using transcriptional fusions for the promoter from each $r s m$ gene, we found a greater increase in $r s m$ expression when nutrient availability declines (Figure 5). Thus, even if growth decreases when nutrients are scarce, as indicated by $\mathrm{OD}_{600 \mathrm{~nm}}$ monitoring in tables beneath each graph of Figure 5, the expression of the four rsm genes highly increases. The greatest effect was observed for $r s m Z$ (Figure 5). Nutrient starvation conditions influenced the expression levels of $r s m$ genes and also certain targets of RsmA/E synthesis, as indicated by an enhancement of protease activity (Figure S1). 

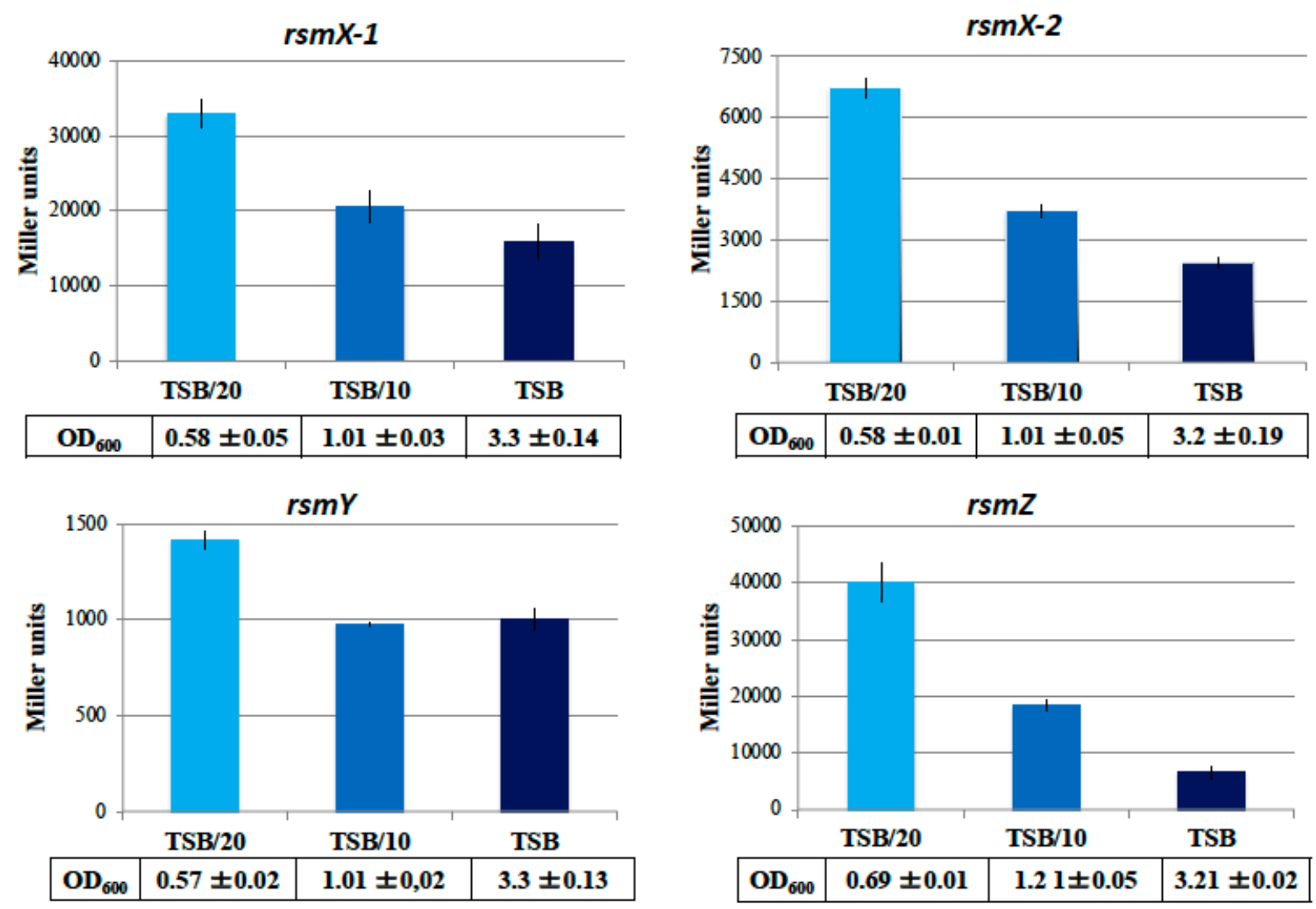

Figure 5. The expression level of $r s m X-1, r s m X-2, r s m Y$ and $r s m Z$ depends on nutrient availability. Activity of a lacZ reporter fused to the promoter regions of $r s m X-1, r s m X-2, r s m Y$ and $r s m Z$ were measured in the P. brassicacearum wild-type strain and are reported as Miller units of $\beta$-galactosidase activity ( \pm standard deviation). The cultures were grown for $24 \mathrm{~h}$ at $30{ }^{\circ} \mathrm{C}$ before being tested and the tables below each graph indicate the $\mathrm{OD}_{600}$ of the cultures. Experiments were conducted in triplicates.

\subsection{Stability of Rsm sRNA}

If most sRNAs indeed regulate translational efficiency, their turnover in varying environments deserves a closer examination. For this, we examined the stability and steady state level of Rsm sRNAs by quantitative real-time reverse transcription polymerase chain reactions (qRT-PCR). We used two different media: TSB/10 and undiluted TSB medium. To determine the in vivo stability of Rsm sRNAs, exponentially phase and late stationary phase growing bacteria were treated with rifampicin to block any further initiation of transcription. Samples were taken at 1, 2, 5, 10, 15, 20, 30, 45, 60, 90 and $120 \mathrm{~min}$ and DNase-treated total RNA was used for qRT-PCR (Table 2, Figure S2). The half-life of each Rsm sRNA was calculated, revealing that these sRNAs are not equally stable. Overall, the half-lives of RsmY and RsmZ are much longer than those of RsmX-1 and RsmX-2 (Table 2, Figure S2).

Table 2. Stability of Rsm sRNAs. Half-lives of P. brassicacearum NFM421 RsmX-1, RsmX-2, RsmY and RsmZ. Experiments were conducted in triplicates.

\begin{tabular}{ccccccc}
\hline \multirow{2}{*}{ Medium } & \multirow{2}{*}{ Phase } & \multicolumn{4}{c}{ Half-Lives in WT (in Min) } \\
\cline { 3 - 6 } & & OD $_{\mathbf{6 0 0 n m}}$ & RsmX-1 & RsmX-2 & RsmY & RsmZ \\
\hline \multirow{2}{*}{ TSB } & Expo & 1.5 & $12 \pm 1.1$ & $5 \pm 0.6$ & $8 \pm 0.2$ & $37 \pm 2.6$ \\
& Stat & 4.5 & $23 \pm 5.4$ & $16 \pm 1.5$ & $45 \pm 5.2$ & $53 \pm 0.9$ \\
\hline \multirow{2}{*}{ TSB $/ 10$} & Expo & 0.5 & $7 \pm 1.5$ & $5 \pm 1.6$ & $8 \pm 1.7$ & $26 \pm 3.6$ \\
& Stat & 0.9 & $37 \pm 4.4$ & $40 \pm 8.6$ & $\geq 60$ & $\geq 90$ \\
\hline
\end{tabular}


The half-life of the four Rsm sRNAs increased during growth to reach their maxima during the stationary phase. For example, RsmX-1 and RsmX-2 stability increased $\sim 8$-fold in TSB/10 in the stationary phase compared to the exponential phase. RsmY and RsmZ were observed to be highly stable with a half-life of at least $60 \mathrm{~min}$ (Table 2, Figure S2).

Moreover, the choice of nutrients condition alters their stability; the four Rsm sRNAs were observed to be more stable in TSB/10 medium at stationary phase (e.g., half-life of RsmY and RsmZ is $>60 \mathrm{~min}$ and $\sim 50 \mathrm{~min}$ in TSB/10 and TSB, respectively). A similar effect was observed for RsmX-1 and RsmX-2, whereas, they both exhibited half-lives of 30-34 min in TSB /10 medium, which were reduced in TSB medium to 23 and $16 \mathrm{~min}$, respectively.

In $P$. brassicacearum, we hypothesize a correlation between the number of GGA motifs and the stability of the four Rsm sRNAs transcripts conferred by RsmA/E. RsmZ, which showed the highest stability, possesses the highest number of GGA motifs (10 with 4-8 exposed); in contrast, RsmX-1 and RsmX-2 have the lowest number of GGA motifs (6 with 3-4 exposed) and were less stable. It should be noted that RsmY is moderately stable, although it only contains 7 GGA motifs (4-5 exposed) (Table 3).

Table 3. Rsm sRNAs stability is correlated to the number of GGA motifs. Relationships between the number of GGA motifs and Rsm sRNAs half-lives of P. brassicacearum NFM421.

\begin{tabular}{ccccc}
\hline & & \multicolumn{2}{c}{ Half-Lives (in Min) } \\
\hline Genes & GGA Motifs & GGA Motifs Exposed & TSB/10 24 h & TSB 24 h \\
\hline RsmX-1 & 6 & $2-4$ & $37 \pm 4.4$ & $23 \pm 5.4$ \\
RsmX-2 & 6 & 3 & $40 \pm 8.6$ & $16 \pm 1.5$ \\
RsmY & 7 & $5-4$ & $\geq 60$ & $45 \pm 5.2$ \\
RsmZ & 10 & $8-7$ & $\geq 90$ & $53 \pm 0.9$ \\
\hline * predicted with Mfold and RNAfold softwares. &
\end{tabular}

\subsection{Stringent Conditions and Sedentary Lifestyle Signalling Molecules}

Given that the Rsm sRNAs expression and stability were increased under starvation conditions and that the bacterial stringent response, is mediated by the ppGpp, we evaluated the production of ppGpp under these culture conditions. Spectra were acquired with a time domain of $4 \mathrm{MW}$ and a total number of 750 scans were accumulated (Figure 6A). As expected, the level of ppGpp is inversely proportional to the availability of nutrients (Figure 6B), while it evolves in the same way as the expression of Rsm sRNAs and in particular rsmZ [34].

Moreover, since Rsm sRNAs promote sedentary state and multicellularity through biofilm formation, a process also coordinated by the bacterial second messenger, cyclic diguanylate monophosphate (c-di-GMP), we also measured its cellular level. The same trend as for ppGpp and Rsm sRNAs was observed, suggesting a link between Gac-Rsm system and these two signal molecules (Figure 6C) as previously shown for other Pseudomonas species [35-37]. 


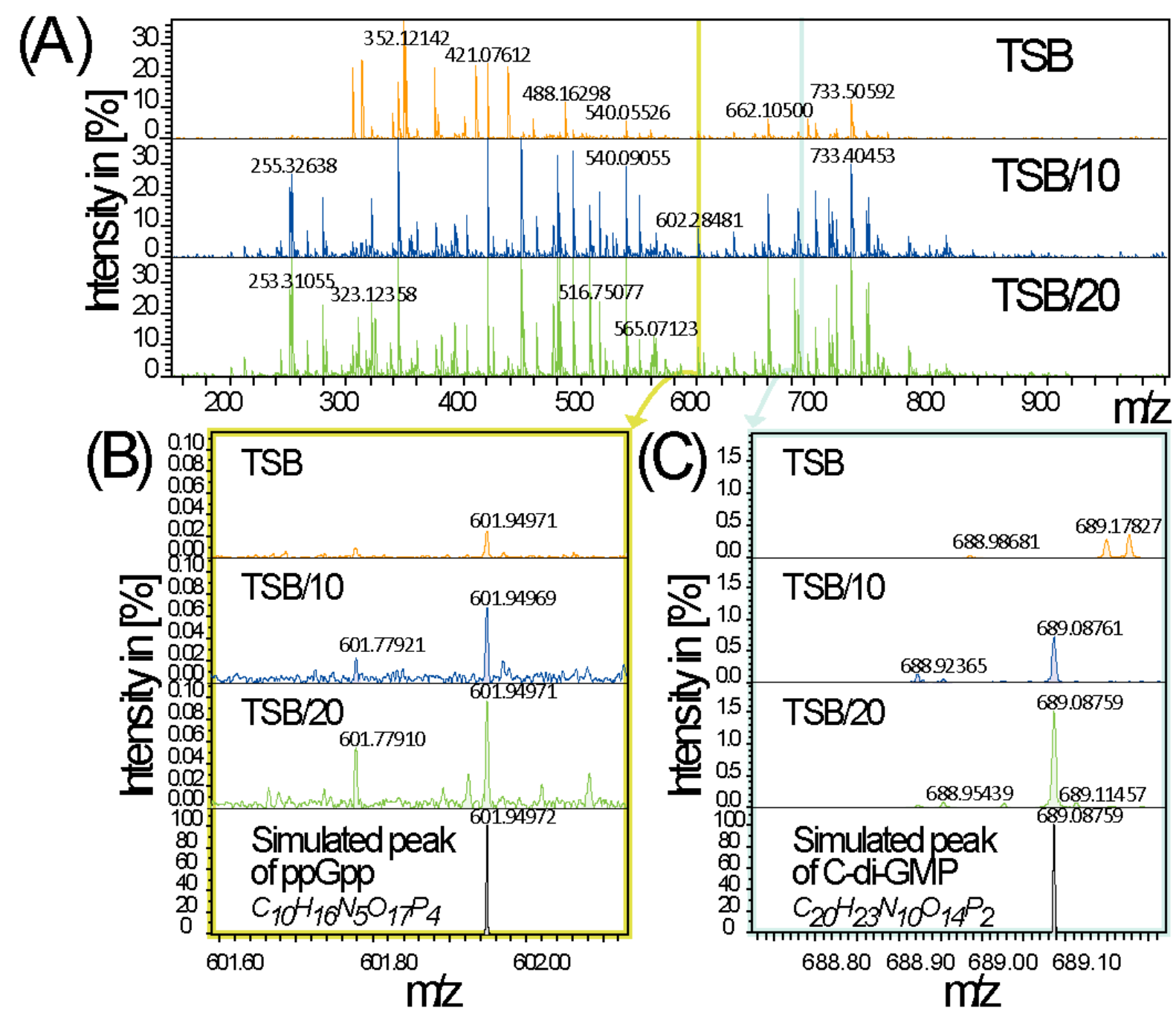

Figure 6. Signal molecules analysis. (A) Full ICR-FT/mass spectra of the wild type (WT) grown in TSB, tenfold dilutes TSB (TSB/10) and twenty-fold diluted TSB (TSB/20). (B,C) detection of (p)ppGpp and c-di-GMP compounds as annotated using metabolome database (MassTRIX: Suhre and Schmitt-Kopplin, 2008).

\section{Discussion}

\subsection{P. brassicacearum Rsm sRNA Amplification by a Duplication of rsmX}

The evolutionary relationships between the $r s m X$ genes indicate the duplication events that occurred in different Pseudomonas species (Figure 2) with up to 5 copies in P. syringae was reported by Moll et al. [8], who correlated the number of Csr/Rsm sRNAs with the number of Csr/Rsm proteins. In E. coli and in most Pseudomonas species, there are two sRNAs for one or two regulatory proteins. However, three to five RsmA homologs are predicted in P. syringae, where up to seven Rsm sRNAs are found [8]. In P. brassicacearum, three RsmA homologs are found: RsmA, RsmE and a third putative RsmA-like protein. Recently, Sobrero and Valverde [11] performed a comparative genomics and evolutionary analysis of Rsm RNAs-binding proteins of the CsrA family in the genus Pseudomonas and suggested that the presence of redundant Rsm proteins that can replace or by-pass each other's activities could help bacteria achieve greater plasticity via post-transcriptional regulation and better noise control in gene expression.

The amplification of regulatory RNAs is not exclusive to Rsm sRNAs. In Vibrio cholerae, four Qrr (quorum regulatory RNA), which are almost 80\% identical in sequence and predicted to have similar secondary structures [3], are involved in virulence and biofilm 
formation [38]. Furthermore, five Qrr sRNAs are involved in the Vibrio harveyi quorumsensing cascade [39]. In different bacterial species, two quite identical sRNAs that control iron homeostasis, as PrrF1 and PrrF2 in Pseudomonas [40] and, RyhB1 and RyB2 in Salmonella [41].

Gene duplication is an important feature in evolution because it provides raw material for adaptation to environmental challenges [42]. This phenomenon is also implicated in enabling gene amplification, and allowing cells to proliferate under growth-limiting conditions [43]. Any environmental condition favouring cells with more copies of a gene would permit them to outgrow the rest of the population in a short time; this includes duplications of rRNA genes that might confer a selective advantage under fast growth rate conditions [44]. Other cases of gene amplification are found in response to antibiotics [45].

Gene duplication-amplification is a frequent process in bacterial genomes, that often disappears after only a few generations of growth in the absence of selection pressure. However, gene copy (ies) may be preserved if they confer an adaptive evolution by increasing gene dosage in response to certain environmental constraints. We previously showed the key role of Rsm sRNAs in activating beneficial traits in plant-associated bacteria as well as virulence genes in phytopathogens $[10,18]$.

\subsection{RsmX-2 Is Part of Gac-Rsm System under Exclusive Control of GacA}

Despite the similarity between the $r s m X-1$ and $r s m X-2$ sequences, the expression of $r s m X-2$ differs from that of $r s m X-1$. The few mutations in the UAS (Figure 1B) of $r s m X-2$ may explain the 8-fold decrease in the expression level. Our data confirm that RsmX-2 sRNA is a member of the Rsm sRNAs family. Indeed, the exclusive overexpression of rsmX-2 in the gac $A$ mutant suppresses the effect of $g a c A$ deletion, suggesting that the four Rsm sRNAs share a redundant function, which appears to be the sequestration of RsmA/E proteins.

In the absence of GacA in P. aeruginosa and P. brassicacearum, transcription of rsm $Y$ and $r s m Z$ is still achieved but to a lesser degree, suggesting the involvement of additional regulatory pathways $[7,18]$. We previously demonstrated the activation of $r s m Z$ expression, which depends on an enhancer sequence located in the rpoS coding region. This suggested the role of additional transcriptional factors as part of the complex network controlling the expression of $r s m Z$. We showed that the conserved palindromic UAS required for GacA-controlled sRNA genes in Gammaproteobacteria is essential but not sufficient for the full expression of the rsmZ gene in P. brassicacearum NFM 421 [46].

Finally, unlike the two novels recently discovered sRNAs, RsmV [47] and RsmW [48], in $P$. aeruginosa, which transcription is independent of the GacS-GacA, rsmX-1 and rsmX-2 expression is exclusively GacS-GacA-dependent.

\subsection{Regulation of the Amount of RNA by Degradation}

sRNAs often modulate mRNA targets stability, notably by recruitment of RNases [49]. This indicates that degradation is a regulatory process, by which bacteria adjust the translation of certain transcripts in response to changing environments. However, turnover of Csr/Rsm sRNAs has not been well-reported in the literature, with the exception of a study reported by Suzuki et al. [50]. These authors identified a regulatory protein (CsrD) that targets the global regulatory RNAs CsrB and CsrC for degradation by RNase E. Investigation of Rsm sRNAs degradation in P. brassicacearum indicates that the half-lives of the four Rsm sRNAs increase in the stationary phase and when nutrients are limited. The rate of turnover for Rsm sRNAs thus seems to be related to growth conditions and cell physiology. Furthermore, the four Rsm sRNAs are not equally stable, with RsmZ appearing to be extremely stable even during the exponential phase (Table 2).

Regulation of RNA amount by degradation is achieved by ribonucleases (RNases), whose activity is dependent on the sequence and/or the structural elements of the RNA molecule. In Salmonella enterica serovar Typhimurium, the endoribonuclease RNase III has 
been shown to regulate MicA (an sRNA involved in porin regulation) in a target-coupled way, whereas RNase E is responsible for the control of free MicA levels in the cell [51].

We hypothesize that the observed differences in Rsm sRNAs are mainly due to the sequence and structural elements of each Rsm sRNA. In P. protegens CHA0, the estimated half-lives of RsmY and RsmZ are $>20 \mathrm{~min}$ in the wild-type and $<10 \mathrm{~min}$ in the $r s m A$ rsmE double mutant [52]. RsmA/E appears to stabilize Rsm sRNAs in vivo probably by protecting them from degradation by RNases. In Erwinia carotovora subsp. carotovora, RsmA also increases the half-life of the RsmB riboregulator [53]. Higher levels of RsmB RNA in the $r s m A^{+}$strain than in the $r s m A^{-}$strain were shown to be due to the increase in RsmB stability and not to an increase in transcription.

It has been suggested that RNase E and Hfq have similar (AU-rich) target sequences that should permit Hfq to protect sRNA from RNase E attack [54]. In P. aeruginosa, RsmY has been described as stabilized by Hfq, which sequesters RNase E cleavage sites [55], and thus enhances RsmA sequestration by RsmY [56]. In P. brassicacearum, an interaction of Hfq with RsmY and RsmZ may explain the extreme stability of these two sRNAs. Nevertheless, in P. aeruginosa, Hfq doesn't affect RsmZ stability, whereas in P. brassicacearum, RsmZ exhibits an A-U rich loop, which could interact with Hfq.

\subsection{Modulation of Rsm sRNAs Expression in Response to Nutrient-Poor Conditions}

The stimuli that activate the Gac-Rsm system are still unknown [57]. In this study, we demonstrated that $r s m$ genes are highly up-regulated under nutrient-poor conditions. Even if Rsm sRNAs are principally synthesized in the stationary phase, our results indicate that their expression is not only related to cellular density, but also and essentially to the physiological and metabolic state of cells. According to carbon source nature and availability, certain metabolites may accumulate within cells and induce specific responses. In $P$. protegens $\mathrm{CHA} 0$, pools of 2-oxoglutarate, succinate, and fumarate were shown to be positively correlated with the expression level of $r s m$ genes [58]. Moreover, the expression of Rsm sRNAs is attenuated in the double mutant relA spoT, for which ppGpp synthesis has been completely abolished [34]. Our data show an activation of (p)ppGpp synthesis in response to nutrient starvation, correlating well with an increase of the four Rsm sRNAs in P. brassicacearum NFM421.

Another signaling molecule, the cyclic-di-GMP second messenger, which modulates the transition from the planktonic to the biofilm state [59], was shown to be positively regulated by GacS-GacA system in P. aeruginosa [35,37]. More recently, Liang et al. [36] showed that the QS system and polyketide antibiotic 2,4-DAPG production are regulated by c-di-GMP through RsmA and RsmE proteins in P. fluorescens 2P24. Our work also suggests a connection between the Gac-Rsm cascade and the c-di-GMP signaling pathway in phytobeneficial Pseudomonas.

Surprisingly, under circumstances that are not advantageous for P. brassicacearum proliferation, such as when nutrients are depleted, bacteria favor the activation of $r s m$ expression and enhance their stability and increase (p)ppGpp and c-di-GMP intracellular levels. Consequently, production of certain secondary metabolites and biofilm formation might be enhanced, suggesting their importance in the adaptive response to environmental constraints.

Based on the present results and those of previous studies [34,36], we propose a model according to which ppGpp as well as c-di-GMP are directly or indirectly positively regulated by GacS/GacA system under nutrient limitations conditions (Figure 7). 


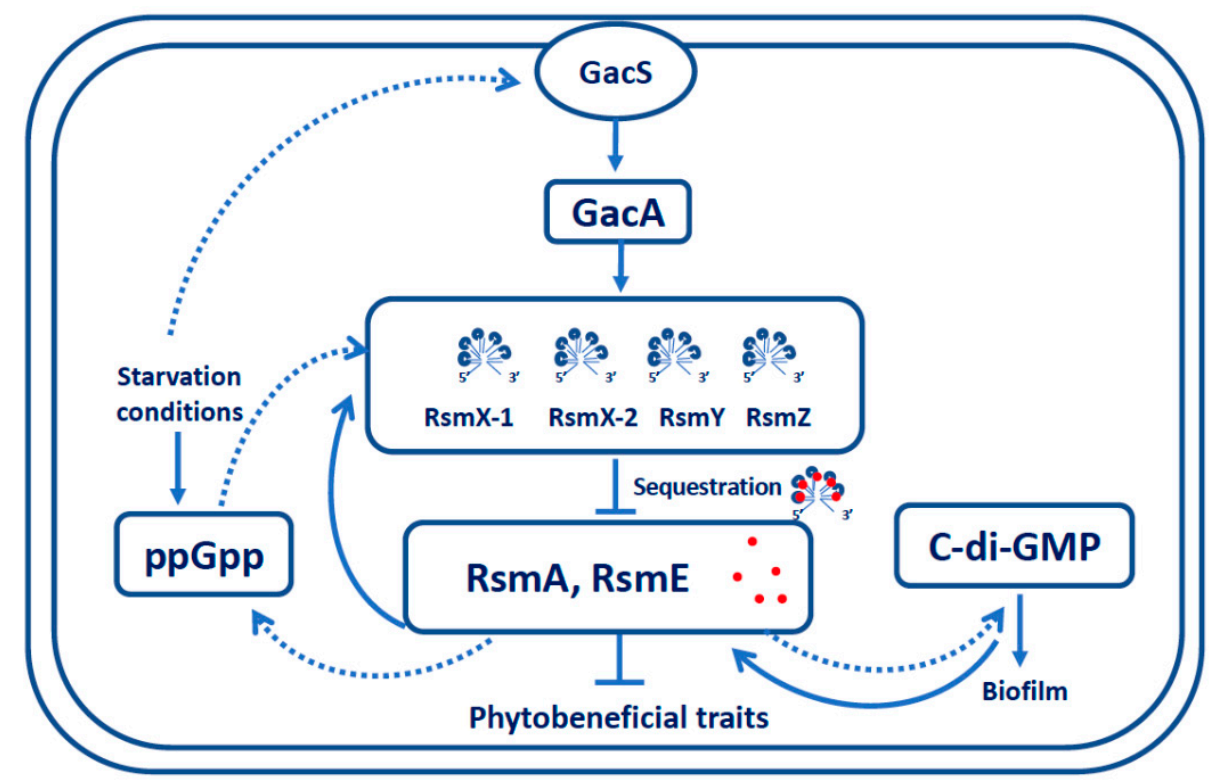

Figure 7. Model for gene regulation by ppGpp and c-di-GMP in the Gac-Rsm system of P. brassicacearum NFM421. This pathway is supported by evidence from this work and previous studies (Lalaouna et al., 2012, Takeuchi et al., 2012, Liang et al., 2020). $\downarrow$, positive effect; $\perp$, negative effect, dotted lines, indirect effects. The new conclusion of this study is that starvation conditions seem to activate the Gac-Rsm system concomitantly with the production of ppGpp and c-di-GMP.

\section{Conclusions}

The amplification of Rsm sRNAs and the preservation of several active copies indicate the importance of this post-transcriptional regulation, which allows the bacterium to increase its plasticity by rapidly adjusting its physiology in response to environmental constraints.

The existence of multiple factors devoted to $r s m$ expression and degradation, illustrates that bacteria have evolved versatile mechanisms to control Rsm sRNAs levels. The higher expression level and the greater stability of the four Rsm sRNAs when nutrient conditions are limited underscore their relevance in the ecological niche of $P$. brassicacearum, a soil in which nutrients are poorly available. It is particularly interesting to note that this transcriptional activation of the four Rsm sRNAS occurs in concert with the increase in the intracellular level of the two signal molecules, (p)ppGpp and c-di-GMP under stringency conditions.

The differences observed in expression and stability between the four Rsm sRNAs illustrate that the subtleties of their respective roles in bacterial adaptation to challenging conditions remain far from being completely understood, as well as the regulation network involving (p)ppGpp and c-diGMP. This definitively deserves to be investigated in further detail.

Finally, although Rsm sRNA concentrations in the cell vary due to noise in gene expression and transcript stability, the overall combined concentrations of each Rsm sRNA are probably maintained in homeostatic balance.

Supplementary Materials: The following are available online at https:/ /www.mdpi.com/2076-260 7/9/2/250/s1. Table S1. Primers: plasmids and strains used in this study. Figure S1. Detection of protease activity under nutrient starvation conditions. (A) Wild-type and gacA strains on TSA/20 lec, on TSA $1 / 10$ lec and on undiluted TSA lec media. (B) Halo thickness (distance from bacteria to halo edge) is expressed as the mean of three measurements, in $\mathrm{cm}$. lec means Skimmed milk (10/\%) was added to growth medium. Figure S2. Rsm RNA stability. In vivo assay of Rsm RNA degradation of P. brassicacearum NFM421 culture at exponential and stationary growth phases under nutrient replete and deplete conditions and rifampicin treatment. Samples were taken after 5, 15, 30, 45, 60, 90, 120, 
150 and 180 min for RNA extraction and q-RT-PCR analysis. Data were normalized to the values obtained from the analysis of $16 \mathrm{~S}$ rRNA as an internal control.

Author Contributions: Conceptualization, D.L. and W.A.; D.L. performed DNA and RNA experiments; S.F. contributed to RNA decay experiments; M.H. performed metabolites analysis; P.O. performed phylogeny analysis; writing-original draft preparation, D.L.; writing-review and editing, W.A., T.H., M.H., P.O., P.S.-K. and D.L. All authors have read and agreed to the published version of the manuscript.

Funding: This research received no external funding.

Institutional Review Board Statement: Not Applicable.

Informed Consent Statement: Not Applicable.

Data Availability Statement: All data in this article is openly available without any restrictions.

Acknowledgments: This work was supported by IRTELIS PhD program Grant from CEA.

Conflicts of Interest: The authors declare that the research was conducted in the absence of any commercial or financial relationships that could be construed as a potential conflict of interest.

\section{References}

1. Romeo, T. Global regulation by the small RNA-binding protein CsrA and the non-coding RNA molecule CsrB. Mol. Microbiol. 1998, 29, 1321-1330. [CrossRef] [PubMed]

2. Fortune, D.R.; Suyemoto, M.; Altier, C. Identification of CsrC and characterization of its role in epithelial cell invasion in Salmonella enterica serovar Typhimurium. Infect. Immun. 2006, 74, 331-339. [CrossRef] [PubMed]

3. Lenz, D.H.; Miller, M.B.; Zhu, J.; Kulkarni, R.V.; Bassler, B.L. CsrA and three redundant small RNAs regulate quorum sensing in Vibrio cholerae. Mol. Microbiol. 2005, 58, 1186-1202. [CrossRef] [PubMed]

4. Sahr, T.; Bruggemann, H.; Jules, M.; Lomma, M.; Albert-Weissenberger, C.; Cazalet, C.; Buchrieser, C. Two small ncRNAs jointly govern virulence and transmission in Legionella pneumophila. Mol. Microbiol. 2009, 72, 741-762. [CrossRef] [PubMed]

5. Heroven, A.K.; Bohme, K.; Rohde, M.; Dersch, P. A Csr-type regulatory system, including small non-coding RNAs, regulates the global virulence regulator RovA of Yersinia pseudotuberculosis through RovM. Mol. Microbiol. 2008, 68, 1179-1195. [CrossRef] [PubMed]

6. Kay, E.; Dubuis, C.; Haas, D. Three small RNAs jointly ensure secondary metabolism and biocontrol in Pseudomonas fluorescens CHA0. Proc. Natl. Acad. Sci. USA 2005, 102, 17136-17141. [CrossRef]

7. Kay, E.; Humair, B.; Denervaud, V.; Riedel, K.; Spahr, S.; Eberl, L.; Valverde, C.; Haas, D. Two GacA-dependent small RNAs modulate the quorum-sensing response in Pseudomonas aeruginosa. J. Bacteriol. 2006, 188, 6026-6033. [CrossRef]

8. Moll, S.; Schneider, D.J.; Stodghill, P.; Myers, C.R.; Cartinhour, S.W.; Filiatrault, M.J. Construction of an rsmX co-variance model and identification of five rsmX non-coding RNAs in Pseudomonas syringae pv. tomato DC3000. RNA Biol. 2010, 7, 3-11. [CrossRef]

9. White, D.; Hart, M.E.; Romeo, T. Phylogenetic distribution of the global regulatory gene csrA among eubacteria. Gene 1996, 182, 221-223. [CrossRef]

10. Harfouche, L.; Haichar, F.Z.; Achouak, W. Small regulatory RNAs and the fine-tuning of plant-bacteria interactions. New Phytol. 2015, 206, 98-106. [CrossRef]

11. Sobrero, P.M.; Valverde, C. Comparative genomics and evolutionary analysis of Rna-binding proteins of the CsrA family in the genus pseudomonas. Front. Mol. Biosci. 2020, 7, 127. [CrossRef] [PubMed]

12. Babitzke, P.; Romeo, T. CsrB sRNA family, sequestration of RNA-binding regulatory proteins. Curr. Opin. Microbiol. 2007, 10, 156-163. [CrossRef] [PubMed]

13. Gebhardt, M.J.; Kambara, T.K.; Ramsey, K.M.; Dove, S.L. Widespread targeting of nascent transcripts by RsmA in Pseudomonas aeruginosa. Proc. Natl. Acad. Sci. USA 2020, 117, 10520-10529. [CrossRef] [PubMed]

14. Liu, M.Y.; Gui, G.; Wei, B.; Preston, J.F.; Oakford, L.; Yuksel, U.; Giedroc, D.P.; Romero, T. The RNA molecule CsrB binds to the global regulatory protein CsrA and antagonizes its activity in Escherichia coli. J. Biol. Chem. 1997, 272, 17502-17510. [CrossRef] [PubMed]

15. Weilbacher, T.; Suzuki, K.; Dubey, A.K.; Wang, X.; Gudapaty, S.; Morozov, I.; Baker, C.S.; Georgellis, D.; Babitzke, P.; Romeo, T. A novel sRNA component of the carbon storage regulatory system of Escherichia coli. Mol. Microbiol. 2003, 48, 657-670. [CrossRef]

16. Valverde, C. Artificial sRNAs activating the Gac/Rsm signal transduction pathway in Pseudomonas fluorescens. Arch. Microbiol. 2009, 191, 349-359. [CrossRef]

17. Brencic, A.; McFarland, K.A.; McManus, H.R.; Castang, S.; Mogno, I.; Dove, S.L.; Lory, S. The GacS/GacA signal transduction system of Pseudomonas aeruginosa acts exclusively through its control over the transcription of the RsmY and RsmZ regulatory small RNAs. Mol. Microbiol. 2009, 73, 434-445. [CrossRef] 
18. Lalaouna, D.; Fochesato, S.; Sanchez, L.; Schmitt-Kopplin, P.; Haas, D.; Heulin, T.; Achouak, W. Phenotypic switching involves GacS- and GacA-dependent Rsm small RNAs in Pseudomonas brassicacearum. Appl. Environ. Microbiol. 2012, 78, $1658-1665$. [CrossRef]

19. Humair, B.; Wackwitz, B.; Haas, D. GacA-controlled activation of promoters for small RNA genes in Pseudomonas fluorescens. Appl. Environ. Microbiol. 2010, 76, 1497-1506. [CrossRef]

20. Bordi, C.; Lamy, M.C.; Ventre, I.; Termine, E.; Hachani, A.; Fillet, S.; Roche, B.; Bleves, C.; Méjean, V.; Lazdunski, A.; et al. Regulatory RNAs and the HptB/RetS signalling pathways fine-tune Pseudomonas aeruginosa pathogenesis. Mol. Microbiol. 2010, 76, 1427-1443. [CrossRef]

21. Achouak, W.; Sutra, L.; Heulin, T.; Meyer, J.M.; Fromin, N.; Degraeve, S.; Christen, R.; Gardan, L. Pseudomonas brassicacearum sp. nov and Pseudomonas thivervalensis sp nov.; two root-associated bacteria isolated from Brassica napus and Arabidopsis thaliana. Int. J. Syst. Evol. Microbiol. 2000, 50, 9-18. [CrossRef] [PubMed]

22. Achouak, W.; Conrod, S.; Cohen, V.; Heulin, T. Phenotypic variation of Pseudomonas brassicacearum as a plant root-colonization strategy. Mol. Plant-Microbe Interact. 2004, 17, 872-879. [CrossRef] [PubMed]

23. Achouak, W.; Conrod, S.; Robert, S.; Heulin, T. Phase variable effects of Pseudomonas brassicacearum on Arabidopsis thaliana root architecture. In Biology of Molecular Plant-Microbe Interactions; Tikhonovich, I., Lugtenberg, B., Provorov, N., Eds.; International Society for Molecular Plant-Microbe Interactions: St. Paul, MN, USA, 2004; Volume 4, pp. 359-363.

24. Chabeaud, P.; de Groot, A.; Bitter, W.; Tommassen, J.; Heulin, T.; Achouak, W. Phase-variable expression of an operon encoding extracellular alkaline protease, a serine protease homolog, and lipase in Pseudomonas brassicacearum. J. Bacteriol. 2001, 183, 2117-2120. [CrossRef] [PubMed]

25. Tillett, D.; Burns, B.P.; Neilan, B.A. Optimized rapid amplification of cDNA ends (RACE) for mapping bacterial mRNA transcripts. Biotechniques 2000, 28, 448-456. [CrossRef] [PubMed]

26. Heeb, S.; Blumer, C.; Haas, D. Regulatory RNA as mediator in GacA/RsmA-dependent global control of exoproduct formation in Pseudomonas fluorescens CHA0. J. Bacteriol. 2002, 184, 1046-1056. [CrossRef]

27. Schnider-Keel, U.; Seematter, A.; Maurhofer, M.; Blumer, C.; Duffy, B.; Gigot-Bonnefoy, C.; Reimmann, C.; Notz, R.; Defago, G.; Haas, D.; et al. Autoinduction of 2,4-diacetylphloroglucinol biosynthesis in the biocontrol agent Pseudomonas fluorescens CHA0 and repression by the bacterial metabolites salicylate and pyoluteorin. J. Bacteriol. 2000, 182, 1215-1225. [CrossRef]

28. Boisset, S.; Geissmann, T.; Huntzinger, E.; Fechter, P.; Bendridi, N.; Possedko, M.; Chevalier, C.; Helfer, A.C.; Benito, Y.; Jacquier, A.; et al. Staphylococcus aureus RNAIII coordinately represses the synthesis of virulence factors and the transcription regulator Rot by an antisense mechanism. Genes Dev. 2007, 21, 1353-1366. [CrossRef]

29. Newell, P.D.; Monds, R.D.; O'Toole, G.A. LapD is a bis- $\left(3^{\prime}, 5^{\prime}\right)$-cyclic dimeric GMP-binding protein that regulates surface attachment by Pseudomonas fluorescens Pf0-1. Proc. Natl. Acad. Sci. USA 2009, 106, 3461-3466. [CrossRef]

30. Suhre, K.; Schmitt-Kopplin, P. MassTRIX: Mass translator into pathways. Nucl. Acids Res. 2008, 36, W481-W484. [CrossRef]

31. Darty, K.; Denise, A.; Ponty, Y. VARNA, Interactive drawing and editing of the RNA secondary structure. Bioinformatics 2009, 25, 1974-1975. [CrossRef]

32. Lapouge, K.; Schubert, M.; Allain, F.H.T.; Haas, D. Gac/Rsm signal transduction pathway of gamma-proteobacteria, from RNA recognition to regulation of social behaviour. Mol. Microbiol. 2008, 67, 241-253. [CrossRef]

33. Edwards, A.N.; Patterson-Fortin, L.M.; Vakulskas, C.A.; Mercante, J.W.; Potrykus, K.; Vinella, D.; Camacho, M.I.; Fields, J.A.; Thopson, S.A.; Georgellis, D.; et al. Circuitry linking the Csr and stringent response global regulatory systems. Mol. Microbiol. 2011, 80, 1561-1580. [CrossRef] [PubMed]

34. Takeuchi, K.; Yamada, K.; Haas, D. ppGpp controlled by the Gac/Rsm regulatory pathway sustains biocontrol activity in Pseudomonas fluorescens CHA0. Mol. Plant Microbe Interact. 2012, 25, 1440-1449. [CrossRef] [PubMed]

35. Moscoso, J.A.; Mikkelsen, H.; Heeb, S.; Williams, P.; Filloux, A. The Pseudomonas aeruginosa sensor RetS switches type III and type VI secretion via c-di-GMP signalling. Environ. Microbiol. 2011, 13, 3128-3138. [CrossRef] [PubMed]

36. Liang, F.; Zhang, B.; Yang, Q.; Zhang, Z.; Zheng, D.; Zhang, L.Q.; Yan, Q.; Wu, X. Cyclic-di-GMP regulates the quorum-sensing system and the biocontrol activity of Pseudomonas fluorescens 2P24 through RsmA and RsmE proteins. Appl. Environ. Microbiol. 2020. [CrossRef]

37. Frangipani, E.; Visaggio, D.; Heeb, S.; Kaever, V.; Camara, M.; Visca, P.; Imperi, F. The Gac/-Rsm and cyclic-di-GMP signalling networks coordinately regulate iron uptake in Pseudomonas aeruginosa. Environ. Microbiol. 2014, 16, 676-688. [CrossRef]

38. Hammer, B.K.; Bassler, B.L. Regulatory small RNAs circumvent the conventional quorum sensing pathway in pandemic Vibrio cholerae. Proc. Natl. Acad. Sci. USA 2007, 104, 11145-11149. [CrossRef]

39. Rutherford, S.T.; Valastyan, J.S.; Taillefumier, T.; Wingreen, N.S.; Bassler, B.L. Comprehensive analysis reveals how single nucleotides contribute to noncoding RNA function in bacterial quorum sensing. Proc. Natl. Acad. Sci. USA 2015, 112, E6038E6047. [CrossRef]

40. Wilderman, P.J.; Sowa, N.A.; FitzGerald, D.J.; FitzGerald, P.C.; Gottesman, S.; Ochsner, U.A.; Vasil, M.L. Identification of tandem duplicate regulatory small RNAs in Pseudomonas aeruginosa involved in iron homeostasis. Proc. Natl. Acad. Sci. USA 2004, 101, 9792-9797. [CrossRef]

41. Padalon-Brauch, G.; Hershberg, R.; Elgrably-Weiss, M.; Baruch, K.; Rosenshine, I.; Mar-galit, H.; Altuvia, S. Small RNAs encoded within genetic islands of Salmonella typhimurium show host-induced expression and role in virulence. Nucleic Acids Res. 2008, 36, 1913-1927. [CrossRef] 
42. Macintyre, R.J. Evolution and ecological value of duplicate genes. Annu. Rev. Ecol. Syst. 1976, 7, 421-468. [CrossRef]

43. Reams, A.B.; Neidle, E.L. Selection for gene clustering by tandem duplication. Annu. Rev. Microbiol. 2004, 58, 119-142. [CrossRef] [PubMed]

44. Anderson, R.P.; Roth, J.R. Tandem genetic duplications in phage and bacteria. Annu. Rev. Microbiol. 1977, 31, 473-505. [CrossRef] [PubMed]

45. Edlund, T.; Grundstrom, T.; Normark, S. Isolation and characterization of DNA repetitions carrying the chromosomal betalactamase gene of Escherichia coli K-12. Mol. Gen. Genet. 1979, 173, 115-125. [CrossRef] [PubMed]

46. Lalaouna, D.; Fochesato, S.; Barakat, M.; Ortet, P.; Achouak, W. Multiple transcription-activating sequences regulate the RsmZ regulatory small RNA of Pseudomonas brassicacearum. J. Bacteriol. 2012, 194, 4888-4893. [CrossRef]

47. Janssen, K.H.; Diaz, M.R.; Gode, C.J.; Wolfgang, M.C.; Yahr, T.L. RsmV, a small noncoding regulatory RNA in Pseudomonas aeruginosa that sequesters RsmA and RsmF from target mRNAs. J. Bacteriol. 2018, 200, e00277-18. [CrossRef]

48. Miller, C.L.; Romero, M.; Karna, S.L.; Chen, T.; Heeb, S.; Leung, K.P. RsmW, Pseudomonas aeruginosa small non-coding RsmAbinding RNA upregulated in biofilm versus planktonic growth conditions. BMC Microbiol. 2016, 16, 155. [CrossRef]

49. Storz, G.; Opdyke, J.A.; Zhang, A. Controlling mRNA stability and translation with small, noncoding RNAs. Curr. Opin. Microbio. 2004, 7, 140-144. [CrossRef]

50. Suzuki, K.; Babitzke, P.; Kushner, S.R.; Romeo, T. Identification of a novel regulatory protein (CsrD) that targets the global regulatory RNAs CsrB and CsrC for degradation by RNase E. Genes Dev. 2006, 20, 2605-2617. [CrossRef]

51. Viegas, S.C.; Silva, I.J.; Saramago, M.; Domingues, S.; Arraiano, C.M. Regulation of the small regulatory RNA MicA by ribonuclease III, a target-dependent pathway. Nucleic Acids Res. 2011, 39, 2918-2930. [CrossRef]

52. Reimmann, C.; Valverde, C.; Kay, E.; Haas, D. Posttranscriptional repression of GacS/GacA-controlled genes by the RNA-binding protein RsmE acting together with RsmA in Biocontrol strain Pseudomonas fluorescens CHA0. J. Bacteriol. 2005, 187, 276-285. [CrossRef] [PubMed]

53. Chatterjee, A.; Cui, Y.; Chatterjee, A.K. RsmA and the quorum-sensing signal, N-[3-oxohexanoyl]-L-homoserine lactone, control the levels of rsmB RNA in Erwinia carotovora subsp. carotovora by affecting its stability. J. Bacteriol. 2002, 184, 4089-4095. [CrossRef] [PubMed]

54. Masse, E.; Escorcia, F.E.; Gottesman, S. Coupled degradation of a small regulatory RNA and its mRNA targets in Escherichia coli. Genes Dev. 2003, 17, 2374-2383. [CrossRef] [PubMed]

55. Sorger-Domenigg, T.; Sonnleitner, E.; Kaberdin, V.R.; Blasi, U. Distinct and overlapping binding sites of Pseudomonas aeruginosa Hfq and RsmA proteins on the non-coding RNA RsmY. Biochem. Biophys. Res. Commun. 2007, 352, 769-773. [CrossRef]

56. Janssen, K.H.; Corley, J.M.; Djapgne, L.; Cribbs, J.T.; Voelker, D.; Slusher, Z.; Nordell, R.; Regulski, E.E.; Kazmierczak, B.I.; McMackin, E.W.; et al. Hfq and sRNA 179 inhibit expression of the Pseudomonas aeruginosa cAMP-Vfr and type III secretion regulons. mBio 2020, 11, e00363-20. [CrossRef] [PubMed]

57. Haas, D.; Defago, G. Biological control of soil-borne pathogens by fluorescent pseudomonads. Nat. Rev. Microbiol. 2005, 3, 307-319. [PubMed]

58. Takeuchi, K.; Kiefer, P.; Reimmann, C.; Keel, C.; Dubuis, C.; Rolli, J.; Vorgolt, J.A.; Haas, D. Small RNA-dependent Expression of Secondary Metabolism Is Controlled by Krebs Cycle Function in Pseudomonas fluorescens. J. Biol. Chem. 2009, $284,34976-34985$. [CrossRef]

59. Romling, U.; Galperin, M.Y.; Gomelsky, M. Cyclic di-GMP: The first 25 years of a universal bacterial second messenger. Microbiol. Mol. Biol. Rev. 2013, 77, 1-52. [PubMed] 